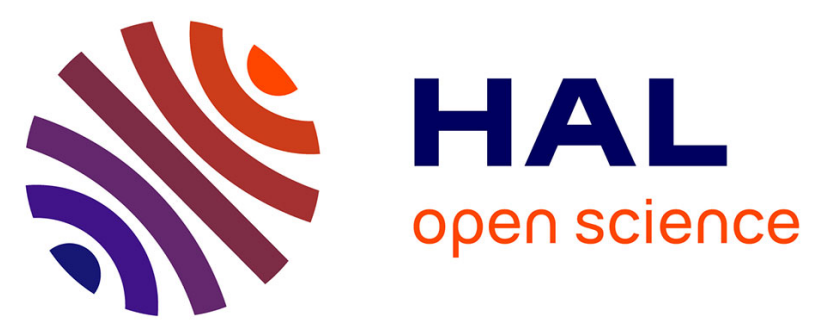

\title{
Tsunami detection by high-frequency radar in British Columbia: performance assessment of the time-correlation algorithm for synthetic and real events
}

Charles-Antoine Guérin, Stéphan T. Grilli, Patrick Moran, Annette Grilli, Tania Insua

\section{To cite this version:}

Charles-Antoine Guérin, Stéphan T. Grilli, Patrick Moran, Annette Grilli, Tania Insua. Tsunami detection by high-frequency radar in British Columbia: performance assessment of the time-correlation algorithm for synthetic and real events. Ocean Dynamics, 2018, 68 (4-5), pp.423-438. 10.1007/s10236018-1139-7 . hal-01780151

\section{HAL Id: hal-01780151 \\ https://hal.science/hal-01780151}

Submitted on 26 Feb 2019

HAL is a multi-disciplinary open access archive for the deposit and dissemination of scientific research documents, whether they are published or not. The documents may come from teaching and research institutions in France or abroad, or from public or private research centers.
L'archive ouverte pluridisciplinaire HAL, est destinée au dépôt et à la diffusion de documents scientifiques de niveau recherche, publiés ou non, émanant des établissements d'enseignement et de recherche français ou étrangers, des laboratoires publics ou privés. 


\title{
Tsunami detection by High Frequency Radar in British Columbia: performance assessment of the Time-Correlation Algorithm for synthetic and real events
}

\author{
Charles-Antoine Guérin • Stéphan T. \\ Grilli • Patrick Moran • Annette R. \\ Grilli · Tania L. Insua
}

Received: date / Accepted: date

\begin{abstract}
The authors recently proposed a new method for detecting tsunamis using High-Frequency (HF) radar observations, referred to as "Time-Correlation Algorithm" (TCA; Grilli et al 2016a,b, 2017). Unlike standard algorithms that detect surface current patterns, the TCA is based on analyzing space-time correlations of radar signal time series in pairs of radar cells, which does not require inverting radial surface currents. This was done by calculating a contrast function, which quantifies the change in pattern of the mean correlation between pairs of neighboring cells upon tsunami arrival, with respect to a reference correlation computed in the recent past. In earlier work, the TCA was successfully validated based on realistic numerical simulations of both the radar signal and tsunami wave trains. Here, this algorithm is adapted to apply to actual data from a HF radar installed in Tofino, BC, for three test cases: 1) a simulated far-field tsunami generated in the Semidi Subduction Zone in the Aleutian Arc; 2) a simulated near-field tsunami from a submarine mass failure on the continental slope off of Tofino; and 3) an event believed to be a meteotsunami, which occurred on October 14th, 2016, off of the Pacific West Coast and was measured by the radar. In the first two cases, the synthetic tsunami signal is superimposed onto the radar signal by way of a
\end{abstract}

\section{C.A. Guérin}

Université de Toulon, Aix Marseille Univ., CNRS IRD, MIO UM110, La Garde, France

E-mail: guerin@univ-tln.fr

S.T. Grilli

Department of Ocean Engineering, University of Rhode Island, Narragansett, RI 02882, USA E-mail: grilli@uri.edu

\section{P. Moran}

Department of Ocean Engineering, University of Rhode Island, Narragansett, RI 02882, USA E-mail: patrick_moran@my.uri.edu

A.R. Grilli

Department of Ocean Engineering, University of Rhode Island, Narragansett, RI 02882, USA E-mail: annette_grilli@uri.edu

\section{T.L. Insua}

Ocean Networks Canada (ONC), 2300 McKenzie Ave., Victoria, BC, VBW 2Y2, Canada E-mail: tinsua@uvic.ca 
current memory term; in the third case, the tsunami signature is present within the radar data. In light of these test cases, we develop a detection methodology based on the TCA, using a correlation contrast function, and show that in all three cases the algorithm is able to trigger a timely early warning.

Keywords High Frequency radar remote sensing · tsunami detection

\section{Introduction}

Tsunamis are among the most destructive natural disasters that can impact highly populated, low lying, coastal areas. In recent past, the world was reminded of their destructive power by the 2004 Indian Ocean (IO) (e.g., Titov et al 2005; Grilli et al 2007; Ioualalen et al 2007) and Tohoku 2011 (e.g., Mori et al 2012; Grilli et al 2013) mega-tsunamis, which caused nearly 250,000 combined fatalities. While their most common generation process is seismicity, tsunamis can be generated by a variety of non-seismic processes, such as volcanic activity (e.g., Abadie et al 2012; Tehranirad et al 2015), submarine mass failure (SMF; e.g., Fine et al 2005; Tappin et al 2008; Grilli et al 2015), and atmospheric disturbances known as meteotsunamis (Monserrat et al 2006; Thomson et al 2009).

Mitigating tsunami coastal impact, particularly loss of life, requires issuing early warnings to the population. In the US, the two NOAA tsunami warning centers, operate around the clock in Hawaii and Alaska to do so, using extensive numerical modeling together with data from a variety of instruments, such as deep water pressure sensors (DART buoys; e.g., Bernard and Titov 2016). Recently, High Frequency (HF) oceanic radars deployed along the shore have proved effective in detecting tsunamis, while they are still a large distance away from shore (see, e.g., Grilli et al 2016a, 2017, and reviews and references therein). Although most of these detections were made in a posteriori reanalyses of radar data (e.g., Lipa et al 2014; Benjamin et al 2016), a HF radar deployed in Tofino, BC (off of the Pacific Ocean side of Vancouver Island) detected a potential meteotsunami in real time on October 14, 2016 (Dzvonkovskaya et al 2017).

The detection of tsunamis by HF radars was first proposed by (Barrick 1979), but it is only in the aftermath of the IO 2004 tsunami that this possibility was confirmed by numerical simulations (e.g., Lipa et al 2006; Heron et al 2008; Gurgel et al 2011; Fuji and Hinata 2017), and following the Tohoku 2011 tsunami in $a$ posteriori reanalyses of radar data (e.g., Hinata et al 2011; Lipa et al 2011, 2012a; Benjamin et al 2016). HF radars can measure properties of the ocean surface (e.g., radial surface current, significant wave height,...) beyond the horizon, over a large sweep area reaching up more than $100 \mathrm{~km}$ offshore (depending on frequency, antenna power, and environmental noise), with a $\sim 120$ degree or greater aperture. In most HF radar systems, radial surface currents are reconstructed over a dense grid of radar cells (a few by a few $\mathrm{km}$ in size), based on the shift they induce in the backscattered Doppler spectrum (so-called Bragg scattering phenomenon; Crombie 1955; Barrick 1972a,b,d,c; Stewart and Joy 1974; Barrick 1978). This ability of $\mathrm{HF}$ radars to provide a dense dataset of time series of radial surface currents, makes them more suitable to detect tsunami currents generated by nonseismic sources (e.g., SMFs, meteotsunamis) than traditional point-based sensors (e.g., pressure or tide gauges). Indeed, such tsunamis can occur at any location 
on or near the continental shelf and shelf break, without the advance warning of an associated strong earthquake to orient the detection of a possibly generated tsunami.

Tsunami Detection Algorithms (TDAs) based on radial surface currents inverted from HF radars have been proposed in some of the studies referred to above, which identify the oscillatory nature of tsunami currents in space and/or time, and TDAs are operational at a few radar locations (e.g., in Tofino, BC). These will be referred to in the following as "Doppler Method" (DM) TDAs. There are, however, some limitations to this detection method (Grilli et al 2016a, 2017). Essentially, to be detectable, tsunami currents must rise above the threshold of accuracy of the Doppler-based estimation, which is inversely proportional to the radar frequency and integration time used to compute the spectrum; thus, estimating small currents requires large integration times. However, this conflicts with the oscillatory nature of tsunami currents, as averaging radar data over a large integration time reduces the estimated current magnitude, making tsunamis less detectable. Hence, one must use a short enough integration time (up to a few minutes) to avoid averaging out tsunami currents. Another limitation is the radar Signal-to-Noise Ratio (SNR), which must remain sufficiently large at the chosen integration time to allow for a reliable estimation of the surface currents. In practice, this limits tsunami detection by way of Doppler shifts to either strong currents (hence on the continental shelf due to shoaling effects), or weak currents but strong SNR (hence in the short ranges), as was for instance the case for the weak 2012 Indonesian tsunami (Lipa et al 2012b). It should be pointed out that, assuming an integration time of a few minutes, this limitation is more important for the shorter period non-seismic tsunamis $(T \sim 5-10 \mathrm{~min})$, than for the longer period co-seismic tsunamis $(T \sim 10-40 \mathrm{~min})$.

To alleviate this limitation of DM-TDAs, (Grilli et al 2016a) proposed a new method, referred to as "Time Correlation Algorithm" (TCA), that does not require inverting currents from Doppler spectra, but instead detects changes in patterns of correlations of radar signal time series, computed between pairs of cells located along pre-computed tsunami wave rays. Performing numerical simulations of both radar signal and tsunami current, for idealized (Grilli et al 2016a) and realistic (Grilli et al 2016b, 2017) seafloor bathymetry and tsunamis, the authors showed that the TCA-TDA, which does not depend on an integration time, may be able to detect weaker tsunami currents (a few $\mathrm{cm} / \mathrm{s}$ ) in deeper water, beyond the continental shelf, without averaging them out. More specifically, (Grilli et al 2017) validated the TCA-TDA using a radar simulator developed using the characteristics of the Tofino WERA HF radar system (manufactured by Helzel Messtechnik $\mathrm{GmbH}$ ), combined with actual measurements of its signal-to-noise ratio (SNR) as a function of range. The simulator was applied to tsunami currents simulated in the area off of Tofino, using a long wave model, for two cases: (i) a Mw 9.1 far-field co-seismic tsunami, sourced in the Semidi Subduction Zone (SSZ; Fig. 1); and (ii) a near-field SMF tsunami triggered on the continental slope, directly off of Tofino (Fig. 2). They concluded that the TCA had the potential to detect the incoming tsunamis further offshore, in deeper water, than using an algorithm based on currents directly inverted from the Doppler spectra (DM). Despite these encouraging results, no definitive conclusions could be drawn before the TCA algorithm was tested using actual radar data. Indeed, besides the idealization of the radar signal in the simulator, the background oceanic currents were also simplified in 
earlier work (as purely random) and ionospheric contamination as well as Radio Frequency Interferences (RFI) were ignored.

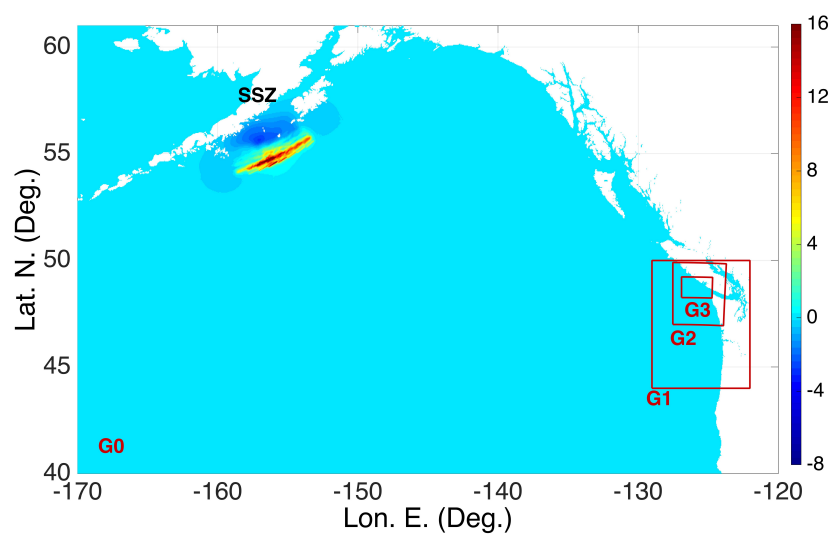

Fig. 1 Zoom-in on part of 2 arc-min grid G0 used in FUNWAVE-TVD's simulations of the $M_{w} 9.1$ co-seismic tsunami sourced in the Semidi Subduction Zone (SSZ); black boxes mark boundaries of nested model grids off of Vancouver Island, BC: G1 (0.6 arc-min), G2 $(270 \mathrm{~m})$, and G3 $(90 \mathrm{~m})$. The color scale (meter) is the initial surface elevation of the SAFRR seismic source used in simulations.

In view of this, in this paper, we first apply the TCA to actual data measured with the Tofino radar (for a few days with different oceanic conditions and wave climate), over which effects of tsunami currents simulated for the same two cases as in (Grilli et al 2017) (Figs. 1, 2) are superimposed. [We refer to (Grilli et al 2017) for details of numerical simulations of tsunami generation and propagation for the SSZ and SMF sources (e.g., Fig. 3).] While one cannot get a tsunami on demand and see its impact on radar data, one can, however, numerically simulate the effects of simulated tsunami currents on measured radar data; this works by introducing, in each radar cell, a phase shift depending on a current memory term (see details below). This technique was already used for instance in (Gurgel et al 2011) to simulate the effects a past tsunami event would have produced on radar data. If not a definitive assessment of an operational TCA-TDA, this approach represents a further step towards a better evaluation of its performance. In a second part we apply the TCA to radar data acquired during an event, which on October 14, 2016 triggered a warning from the DM-TDA that is part of the standard WERA radar system. This event was determined to be a potential meteotsunami event (Dzvonkovskaya et al 2017), although some other long wave phenomena cannot entirely be ruled out, and, hence, this test case represents a fully realistic, albeit offline, validation of the TCA tsunami detection abilities.

\section{$2 \mathrm{HF}$ radar system and data used in this work}

In April 2016, Ocean Networks Canada (ONC) installed a WERA HF radar near Tofino, BC, on the west coast of Vancouver Island (Canada) (Fig. 2), as a com- 


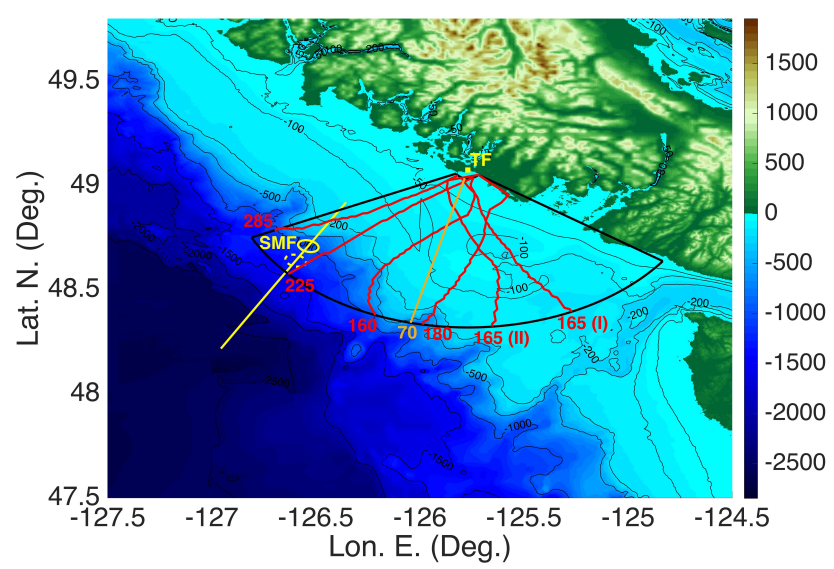

Fig. 2 Bathymetry/topography (color scale and contours) and sweep area (black sector; assuming a $85 \mathrm{~km}$ maximum range) of the WERA HF radar located in Tofino, BC (TF; 1 ). The solid yellow ellipse (centered at 48.70822 Lat. N. and -126.53669 Lon. E.) and dashed line mark the initial SMF footprint $(w=8$ by $b=6 \mathrm{~km})$ and direction of motion (209 deg. clockwise from N), respectively; the dashed ellipse marks its final location $\left(s_{f}=9 \mathrm{~km}\right.$ downslope). The numbered red solid lines mark 6 wave rays selected to apply the TCA-TDA, and the brown line is a selected azimuth (70th).

ponent of their ocean observing systems. This radar was equipped with a commercial tsunami detection software, provided by the Helzel company, with the aim to evaluate real-time tsunami detection by HF radar data on the coast of British Columbia. This radar has a carrier electromagnetic frequency $f_{E M}=13.5 \mathrm{MHz}$ and a $110 \mathrm{~m}$ long array of 12 antennas, centered at $49^{\circ} 4^{\prime} 24.82^{\prime \prime} \mathrm{N}, 125^{\circ} 46^{\prime}$ 11.55 " W, yielding an 85-110 km range, depending on sea state and atmospheric conditions, and a $\sim 12$ deg. azimuthal resolution at the center of the beam. The orientation of the radar array, $275 \mathrm{deg}$. from N, clockwise, and its $120 \mathrm{deg}$. beam opening, yield a sweep area for which one side is nearly parallel to the coastline southeast of Tofino (Fig. 2). In the radar signal processing system, the sweep area is divided into radar cells, within which the received radar signal is averaged (and radial surface currents are inverted). These cells all have a radial length $\Delta R=1.5$ $\mathrm{km}$ and the angular opening $\Delta \phi_{r}=1 \mathrm{deg}$. is used in the beam forming algorithm to process the radar signal in overlapping angular windows; hence cell width and area: $\Delta \mathbb{S}=R \Delta R \Delta \phi_{r}$ increase with range.

In the application of the TCA-TDA to synthetic tsunamis presented later, several days of radar data corresponding to different oceanic conditions will be used (Julian days 200, 227, 238, 287, 289 in 2016), including one day with a strong swell (i.e., day 289 , with a $4.3 \mathrm{~m}$ significant wave height and $10.7 \mathrm{~s}$ peak spectral wave period), over which effects of simulated tsunami currents will be superimposed (see details below). In the application of the TCA-TDA to the detection of the potential meteotsunami event of October 14, 2016, the algorithm will be directly applied to radar data measured on that day (Julian day 288). The main sea state parameters of the different days are summarized in Table 1 . These were extracted from records of a nearby buoy (La Perouse, station C46206), available online on the Canadian Marine Environment Data Service (http://www.meds-sdmm.dfo-mpo.gc.ca). 


\begin{tabular}{|l||l|l|l|l|}
\hline Day & $H_{s}$ & $T_{p}$ & WD & WS \\
\hline $200(0-2)$ & 1.1 & 8.4 & - & - \\
\hline $227(11-13)$ & $2.15-2.41$ & 6.9 & 183 & 9.9 \\
\hline $238(1-2)$ & 1.01 & 6.9 & 36 & 0.2 \\
\hline $287(0-2)$ & 2.75 & 6.9 & 106 & 14.8 \\
\hline $288(6-8)$ & 4.54 & 16 & 183 & 10.1 \\
\hline $289(6-8)$ & 4.32 & 10.7 & 155 & 6 \\
\hline
\end{tabular}

Table 1 Available sea state conditions as recorded at La Perouse Bank station (462006) for the different days of radar data. From left to right column: Julian day (UTC hour of the day), significant wave height $\left(H_{s}\right.$, in $\left.\mathrm{m}\right)$, Wave peak period $\left(T_{p}\right.$, in $\left.\mathrm{s}\right)$, Wind direction (WD, in degree TrueNorth), Wind speed (WS, in $\mathrm{m} / \mathrm{s}$ )

(a)

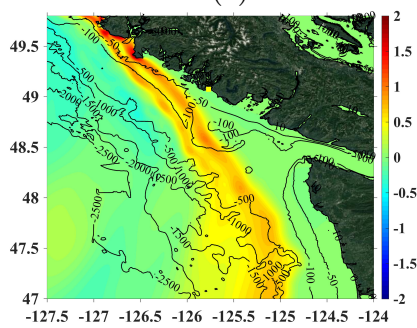

(b)

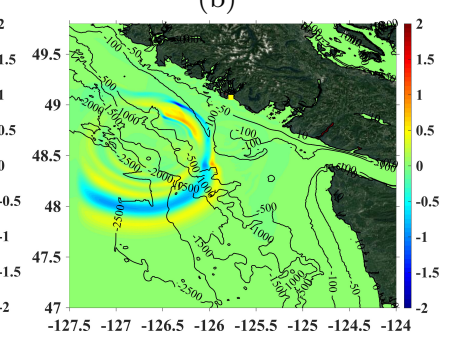

Fig. 3 Instantaneous surface elevations (color scale in meter) simulated in grid G2: (a) with FUNWAVE-TVD for the SSZ source (Fig. 1), at $t=7200 \mathrm{~s}$; b) with NHWAVE for the SMF source (Fig. 2) at $t=800 \mathrm{~s}$.

\section{Simulation of synthetic tsunamis}

In earlier work, (Grilli et al 2016b, 2017) simulated the surface elevations and currents caused by two hypothetical tsunamis, over the Tofino radar sweep area. As indicated above, tsunami currents simulated for the same two sources are used in this paper to test the TCA-TDA, in combination with actual radar data. Details of source parameterization and tsunami generation and propagation simulations can be found in the references.

The first synthetic tsunami was co-seismic and generated by a $M_{w} 9.1$ farfield source located in the Semidi Subduction zone (SSZ; Fig. 1). This source was designed by the SAFRR group as a worst-case scenario for northern California (Kirby et al 2013) and is also a plausible major tsunami case for the Pacific West Coast of Canada. The SSZ tsunami propagation was modeled using the Boussinesq long wave model FUNWAVE-TVD (Shi et al. 2012; Kirby et al. 2013a) by one-way coupling, using a series of nested spherical, then Cartesian, grids of increasingly fine resolution towards the coast of Tofino (G0-G3; Fig. 1; Fig. 3a). The second synthetic tsunami was generated by a near-field SMF of volume $1.7 \mathrm{~km}^{3}$, located in a $980 \mathrm{~m}$ depth on the continental slope, $70 \mathrm{~km}$ off of Tofino (Fig. 2); the SMF geometry was idealized as a sediment mound of quasi-Gaussian shape with 8 by 2 $\mathrm{km}$ elliptical footprint and maximum thickness $100 \mathrm{~m}$ (Fig. 2). The SMF tsunami generation was modeled in grid G2 as a rigid slump with a $s_{f}=9 \mathrm{~km}$ runout, using the non-hydrostatic model NHWAVE (Ma et al 2012; Grilli et al 2015), with 5 boundary conforming layers in the vertical direction. Once generation was completed, simulations were continued with FUNWAVE-TVD in grid G2 and then 
by one-way coupling in grid G3 (Fig. 3b). In both cases shown in Fig. 3, time is measured from the initial time $(t=0)$ corresponding to the initiation of the tsunami wave train at the source. It takes approximately 2 hours and $20 \mathrm{~min}$ for the SSZ tsunami to reach the shore of Vancouver Island near Tofino, and only 20 minutes for the SMF tsunami.

To simulate their effect on radar data, time series of simulated horizontal tsunami currents $\mathbf{u}_{t}$ are projected in the radar radial direction $\mathbf{R}$ as $U_{t r}=\mathbf{u}_{t} \cdot \mathbf{R}$ and spatially-averaged over individual radar cells in the sweep area. Note, as FUNWAVE-TVD's G3 grid 90 m resolution was much smaller than most radar cells' area, a large number of grid cells were averaged to compute tsunami radial current time series within each radar cell. To apply the TCA, many wave rays were computed from a number of assumed incident directions, by solving the wave geometric optic equation for the specified bottom bathymetry. A small number of these rays (6 rays labeled 160 to 285 in Fig. 2) was selected, which covered well the radar sweep area, particularly in its distant shallower parts where currents are stronger. Radar cells aligned along these rays were identified and tsunami propagation times between such cells computed using the linear long wave phase velocity $c=\sqrt{g h}$ (where $g$ is gravitational acceleration and $h$ the depth), also as a function of the local bathymetry. Details of the wave ray and travel time computations can also be found in the references.

\section{The Time-Correlation Algorithm (TCA)}

According to first-order Bragg theory, the complex back-scattered signal received at time $t$ for a given radar cell $q$ is of the form,

$$
\mathrm{V}_{q}(t)=\alpha^{+} e^{-2 \mathrm{i} \pi f_{B} t}+\alpha^{-} e^{+2 \mathrm{i} \pi f_{B} t}
$$

where $\alpha^{ \pm}$are complex constant coefficients, functions of sea state, range, and radar calibration, and $f_{B}=\sqrt{g /\left(\pi \lambda_{E M}\right)}$ is the Bragg frequency $\left(\lambda_{E M}\right.$ is the electromagnetic wavelength). In the presence of a constant radial surface current $U_{r}$, the complex radar signal experiences a Doppler frequency shift $f_{U}=-2 U_{r} / \lambda_{E M}$ and is thus multiplied by a complex exponential $e^{2 \mathrm{i} \pi f_{U} t}$. For a variable current in time, $U_{r}(t)$, the Doppler frequency shift is obtained through the integration of the instantaneous Doppler frequency $f_{U}(t)=-2 U_{r}(t) / \lambda_{E M}$, and the radar time series is thus multiplied by the complex exponential $e^{\mathrm{i} M(t)}$, where,

$$
M(t)=-\frac{4 \pi}{\lambda_{E M}} \int_{-\infty}^{t} U_{r}\left(t^{\prime}\right) d t^{\prime}
$$

is often referred to as a current memory term, since it integrates the past values of the current.

In the presence of a tsunami wave train, the radar signal of Eq. (1) is thus modified as,

$$
\mathrm{V}_{q}(t)=\left(\alpha^{+} e^{-2 \mathrm{i} \pi f_{B} t}+\alpha^{-} e^{+2 \mathrm{i} \pi f_{B} t}\right) e^{\mathrm{i} M(t)}
$$

where the memory term is computed based on the tsunami radial current, spaceaveraged within each radar cell $U_{t r}$.

As seen in tsunami simulations (e.g., Fig. 3) and according to linear long wave theory, the arrival of an incident tsunami wave train within a given sea state, causes 
the appearance of a slowly varying horizontal current propagating at the long wave phase speed $c$, whose amplitude is nearly proportional to the local tsunami elevation and inversely proportional to $\sqrt{h}$. The main principle underlying the TCA, proposed by the authors in earlier work, is to take advantage of the unique large scale coherency of this tsunami-induced current, to identify (i.e., detect) its occurrence in the radar signal through its effect on the memory term $M$. As the tsunami wave train propagates over large distances, refracting along wave rays as a function of its (depth-dependent) phase speed (well approximated by $c$ ), currents induced at successive locations along such a ray should be strongly correlated. More specifically, we expect the strongest correlation to occur between the current $U_{t p}(t)$ at cell $p$ and the time-shifted current $U_{t q}\left(t+t_{p q}\right)$ at cell $q$, where $t_{p q}$ is the tsunami travel time from cell $p$ to cell $q$, and currents used here are projections of $\mathbf{u}_{t}$ on the local wave ray. This property carries over to the memory term and, therefore, also to the radar signal itself, which is modulated by $M$ (see Eq. (3)), assuming that most wave rays at far ranges, where detection is most effective, are directed more or less towards the radar (e.g., Fig. 2) and hence, the effect of projecting currents from the tangential direction to a ray to the radial direction is negligible.

Based on this principle, the TCA calculates correlations of complex backscattered radar signal time series, $V_{p}(t)$ and $V_{q}\left(t-t_{p q}\right)$, received from 2 given cells $p$ and $q$ located along the same tsunami ray, shifted by the tsunami propagation time between these cells (if cell $q$ is located farther offshore than cell $p$, travel time $t_{p q}$ is positive),

$$
C_{p q}(\tau ; t)=\left|\operatorname{corr}\left\{\mathrm{V}_{p}(t+\tau), \mathrm{V}_{q}\left(t-t_{p q}\right)\right\}\right|
$$

as a function of an additional time lag $\tau \in\left[-T_{l} / 2, T_{l} / 2\right]$, with $T_{l}$, the length of the time lag window. With this definition, the maximum signal correlation is expected to occur at $\tau=0$. Hence, a change in pattern of previously computed correlations $C_{p q}$ near $\tau=0$ should indicate that a tsunami is propagating through the radar sweep area. In practice, assuming short time stationarity, the ensemble average is obtained through a temporal average using a running time window in the recent past,

$$
C_{p q}(\tau ; t)=\left|\frac{1}{T_{c}-\tau} \int_{I_{t}} \mathrm{~V}_{p}\left(t^{\prime}+\tau\right) \mathrm{V}_{q}^{*}\left(t^{\prime}-t_{p q}\right) \mathrm{d} t^{\prime}\right|
$$

where the integration is performed over the time interval $I_{t}=\left[t-T_{c}, t-\tau\right]$. Here, $T_{c}>T_{l}$ the length of the time window (i.e., correlation time), which should be sufficiently large to capture a meaningful part of the oscillations of the tsunami current, that is at least one-third to one-half the tsunami dominant period $T_{t}$ (in the following applications we used $T_{c}=900$ to $1200 \mathrm{~s}$ ). Note that in Eq. (5), the integration domain decreases as time lag increases, which is due to the requirement that the calculation of the correlation at the present time does not require knowledge of the radar time series in the future $\left(t^{\prime}+\tau>t\right)$. The reduction of the integration time as lag increases is compensated by the atypical normalization factor $1 /\left|T_{c}-\tau\right|$. This ensures in particular that the correlation of two uniform signals remains flat and prevents the occurrence of an artificial correlation peak near zero time lag. 


\section{Application of the TCA to actual radar data}

We obtained raw signal recorded by the Tofino HF radar system at a sampling rate $\Delta t=0.26 \mathrm{~s}$, for Julian days 200, 227, 238, 287, 289 in 2016 and October 14th, 2016, and processed it in range and azimuth using software developed by Helzel Messtechnik GmbH, to produce time series of complex backscattered signal $\mathrm{V}_{q}(t)$ for each radar cell $q$ located along the selected tsunami rays in the sweep area (Fig. 2). The first 5 days were randomly selected from a larger dataset, as complete days of records representing different oceanic conditions.

Following Eq. (3), the effect of synthetic tsunami currents on radar data was simulated by multiplying the measured radar signal time series by the complex memory term from Eq. (2), computed in each cell based on space-averaged radial currents $U_{t r}$, i.e.,

$$
V_{p} \rightarrow V_{p}(t) \mathrm{e}^{\mathrm{i} M(t)}
$$

To avoid spurious values, which are sometime observed in radar signal time series, and to equalize their magnitude at different ranges, only the re-centered and normalized complex values of the radar signal time series were retained, i.e., we considered signals of the form,

$$
S_{p}(t)=\frac{V_{p}(t)-\overline{V_{p}}}{\left|V_{p}(t)\right|}
$$

where $\overline{V_{p}}$ is the temporal mean of the signal in the window of observation.

Time-shifted, radar signal correlations $C_{p q}(\tau ; t)$ between pairs of cells $(p, q)$ were calculated with Eq. (5), based on $S_{p}(t)$. In each case, the signal at radar cell $p$ was correlated with that at its $K$ th neighbor, $p+K$, for $N$ successive values (that is $p=p_{0}, p_{0}+1, . ., p_{0}+N-1$ ). The $N$ resulting correlations were normalized by their maximum and averaged over the $N$ available pairs,

$$
C_{p_{0}, N, K}(\tau ; t)=\frac{1}{N} \sum_{p=p_{0}}^{p_{0}+N-1} \frac{C_{p, p+K}(\tau ; t)}{\max _{\tau}\left(C_{p, p+K}(\tau ; t)\right)}
$$

A final smoothing in time (here over a $120 \mathrm{~s}$ window) was finally applied to remove higher-frequency oscillations in the average correlation (which had negligible effect on the contrast function detailed later).

Figs. 4a,b show plots of correlations $C_{p_{0}, N, K}(\tau ; t)$ computed as a function of $\tau$, on day 238 , for $p_{0}=31, N=23$ and $K=1$, along rays $160,180,225$ and 285 , at two different times $t=1 \mathrm{~h} 48^{\prime} 09$ " and 1h56'09" into the SSZ tsunami event (red lines), compared to the reference correlation computed using data $1 \mathrm{~h}$ in the past (black dashed lines). By contrast with the idealized cases studied earlier using a radar simulator (Grilli et al 2016a,b, 2017), in which the radar data showed a flat correlation in the absence of a tsunami, here the reference correlation already exhibits a strong correlation peak near the zero time lag, even in the absence of a tsunami. This was first noted by (Guérin et al 2017), who postulated that this is likely an artifact of the radar signal processing algorithms (i.e., rangegating and beam-forming), which are applied to raw data to calculate the rangeand azimuth-resolved radar signal. It is difficult to provide a rigorous explanation for this phenomenon without delving into details of the radar signal processing algorithm. In short, this is due to the fact that the simultaneous signals 
backscattered from neighboring radar cells cannot be exactly uncoupled in the range and azimuthal processing. Comparing time-shifted correlations computed with and without tsunamis, such in Figs. 4c and d, but for more distant cells, would show that this preexisting correlation between cells is stronger than the additional signal correlation resulting from the current memory term. However, even though the computed time-shifted correlations are not flat in the absence of the tsunami, the occurrence of the latter still manifests itself in a measurable way, through an increase of the mean correlation $C_{p_{0}, N, K}$ (Figs. 4a,b). This is due to the highly correlated structure of the memory term caused by the tsunami current, for time-shifted radar cell time series. Hence, tsunami detection can still be easily achieved by observing a clear change in pattern of the mean correlation with respect to some reference level. In an operational way, as already indicated above, the reference correlation of a given sea state in the absence of a tsunami can simply be calculated using the radar signal recorded in the recent past, say $1 \mathrm{~h}$ earlier. During this length of time, while the tsunami wave train has not yet reached the radar cells, both sea state and radar characteristics can be assumed to be quasi-steady.

Therefore, to quantify this change in correlation pattern, a contrast function is introduced defined as,

$$
\Gamma_{p_{0}, N, K}(t)=\frac{\int_{-T_{l} / 4}^{T_{l} / 4}\left(C_{p_{0}, N, K}(\tau ; t)-C_{p_{0}, N, K}^{\mathrm{ref}}(\tau ; t)\right) d \tau}{\int_{-T_{l} / 4}^{T_{l} / 4}\left(C_{p_{0}, N, K}(\tau ; t)+C_{p_{0}, N, K}^{\mathrm{ref}}(\tau ; t)\right) d \tau}
$$

This function quantifies the change in area of the mean correlation $C_{p_{0}, N, K}$ with respect to its reference value $C_{p_{0}, N, K}^{\mathrm{ref}}$, normalized by the sum of the respective areas. Note, only the central half of the correlation lags in the correlation window $T_{l}$ are considered, since the larger lags are less reliable from a numerical point of view. The reference correlation $C_{p_{0}, N, K}^{\text {ref }}$ can simply be taken as a correlation computed in the recent past, that is $C_{p_{0}, N, K}^{\mathrm{ref}}(\tau ; t)=C_{p_{0}, N, K}(\tau ; t-\Delta t)$, for some time shift $\Delta t$ to be defined. In the following applications, we use $\Delta t=1 \mathrm{~h}$, for which meteorological and oceanic conditions are expected to be quasi-steady. This choice also results from a technical convenience, as the radar time series is interrupted in the last 2.5 minutes of each hour for control purposes. Hence, the choice of a onehour time shift for the reference signal makes it possible to process an interrupted subsequent time series of 57.5 minutes.

We also tested several values of the separation distance $K$ between the correlation pairs and found that taking $K=1$ (i.e., using the nearest neighboring cell range-ward) led to computing the most discriminant contrast function. It should be noted that, in this case where correlations are computed for adjacent radar cells, the tsunami travel time between cells is very small (on the order of 20 to $50 \mathrm{~s}$ ) compared to both the time correlation window $T_{c}$ and the dominant tsunami wave period $T_{t}$; hence we observed that ignoring this travel time (i.e., setting $t_{p q}=0$ in Eq. (4)) had negligible effects on the contrast function. The results below were nevertheless computed using the travel times. 
(a)

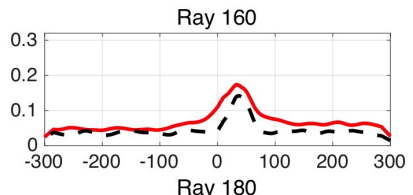
Ray 180

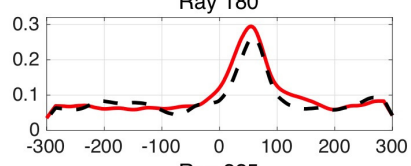

Ray 225
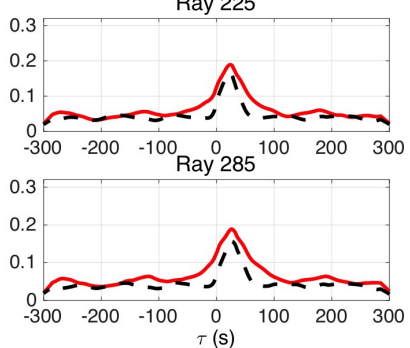

(c)

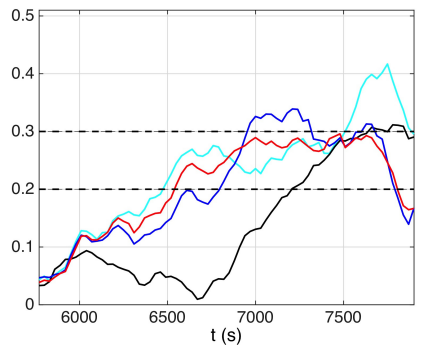

(b)

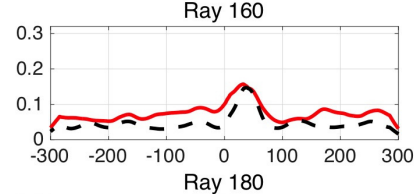

Ray 180

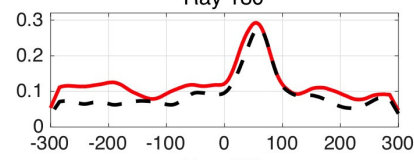

Ray 225
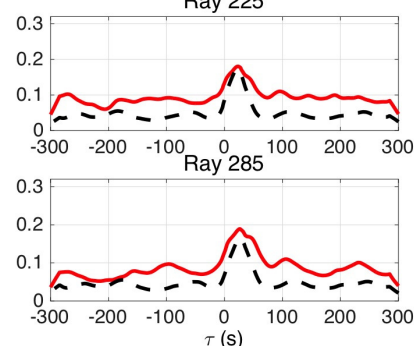

(d)

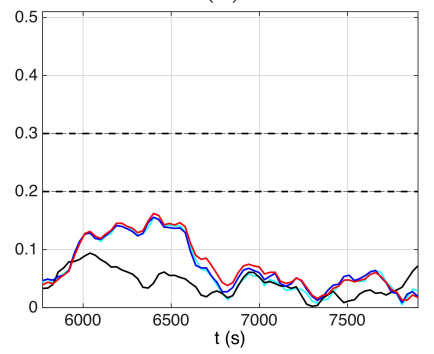

Fig. 4 (a) and (b), mean correlations $C_{31,23,1}$ (red solid lines) and their reference values (black dashed lines) computed as a function of time lag $\tau$ for the SSZ tsunami, using radar data from day 238, at $t=$ (a) 1h48' (first warning); and (b) 1h56' (alert confirmation). [The correlations have been smoothed with a $120 \mathrm{~s}$ window.] (c) Time series of contrast function $\Gamma_{31,23,1}$ computed along rays: (cyan) 160, (black) 180, (blue) 225, and (red) 285; based on a low and high contrast threshold 0.2 and 0.3 , respectively (horizontal dashed lines), a first warning would be issued at $6,480 \mathrm{~s}\left(1 \mathrm{~h} 48^{\prime}\right)$ and an alert confirmation at $6,960 \mathrm{~s}\left(1 \mathrm{~h} 56^{\prime}\right)$ into the event. (d) Same as (c), with no synthetic tsunami current added.

\section{Application of the TCA to synthetic tsunami detection}

6.1 The far-field SSZ co-seismic tsunami

Fig. 4 shows the mean correlation $C_{31,23,1}(\tau)$ and corresponding contrast function $\Gamma_{31,23,1}(t)$ (with and without the tsunami), computed along 4 tsunami wave rays marked in Fig. 2 (160, 180, 225 and 285), as a function of time lag $\tau$ and time $t$, respectively. In the correlations, time series of radar signal measured in cells 31 to 53 (corresponding to ranges from 45 to $79.5 \mathrm{~km}$ ) are correlated with those in the neighboring cells range-ward (i.e., cells 32 to 54), using an integration window $T_{c}=1,200 \mathrm{~s}$. The figure shows results based on data measured on Julian day 238 
in 2016 (on which the synthetic tsunami current effect was superimposed), but several days of radar data corresponding to different oceanic conditions were tested (Julian days 200, 227, 238, 287, 289 in 2016). Figs. 4a, b show the mean correlation (here smoothed over a $120 \mathrm{~s}$ moving window) and Figs. 4c, d the contrast function with and without tsunami currents. In Fig. 4c, a clear increase in contrast can be observed as the tsunami wave train propagates across the radar cells. Based on a low contrast threshold of 0.2 , a first warning could be issued at $t=6,480 \mathrm{~s} \mathrm{(1h48')}$ while a confirmation (i.e., an alert) could be issued at $t=6,960 \mathrm{~s}$ (1h56') based on a higher contrast threshold of 0.3. This is confirmed in Figs. 4a,b, which show average correlations computed at these critical times for cells 31 to 53, along the 4 selected wave rays; a clear change in pattern of these correlations can be observed with respect to the reference correlations (calculated based on data $1 \mathrm{~h}$ in the past). To confirm the relevance of this alert, the contrast functions were also calculated In Fig. 4d using the same radar data time series, but without superimposing the memory term based on the tsunami current (Eq. (6)); the contrast functions clearly remain below both low and high contrast thresholds. It is interesting to note that the detection based on the contrast function is effective even though the magnitude of the tsunami-induced currents is small in cells 31 to 53. This can be seen in Fig. 5, which shows the time evolution of radial tsunami surface currents $U_{t r}(t)$ calculated in these cells, along the ray 225, from FUNWAVE-TVD's simulations of the SSZ source. At the time of first warning (1h48'), the magnitude of tsunami-induced currents is less than $7.5 \mathrm{~cm} / \mathrm{s}$, except in the 3 shallowest radar cells (31-33), where it reaches up to $17 \mathrm{~cm} / \mathrm{s}$. Similar results and detection times (not shown) were obtained using radar data for the other 4 selected days, even on day 289, which had a strong swell.

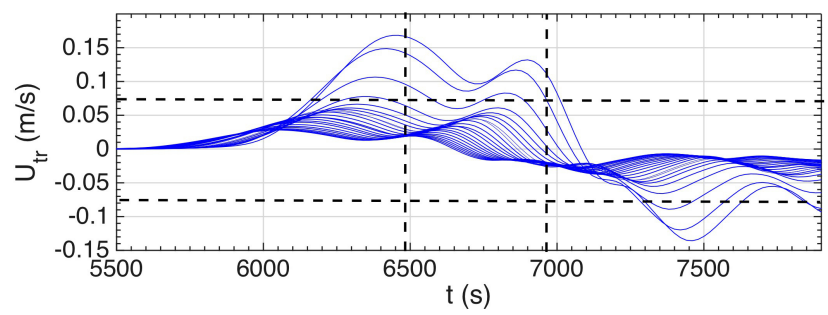

Fig. 5 Time series of radial surface currents induced by the SSZ tsunami (Figs. 1 and 3a) computed at radar cells 31 to 53 along ray 225 (Fig. 2) using FUNWAVE-TVD. The vertical dashed lines mark the time of first warning (1h48') and alert (1h56'), while the horizontal dashed lines mark the region with a $\pm 7.5 \mathrm{~cm} / \mathrm{s}$ current magnitude.

\subsection{The near-field SMF tsunami}

The same numerical experiment was repeated using the SMF tsunami currents, for the same radar cells, rays, and radar time series of different hours and days. Due to the smaller time scales involved, a smaller integration time $T_{c}=900 \mathrm{~s}$ was used. Fig. 6 shows an example of the contrast function $\Gamma_{31,23,1}$ computed on Julian day 
238 with (a) and without (b) a superimposed tsunami current. In the presence of the latter, a first warning could be issued 6 min 9 s into the event, using rays 225 and 285 , and a confirmation could be given at 8 min $39 \mathrm{~s}$. Numerical experiments using several other hours and days worth of data revealed a stable pattern for the evolution of the contrast function, regardless of the oceanic conditions, and showed that the highest threshold (here a value of 0.3 ) is never reached in the absence of a tsunami.

(a)

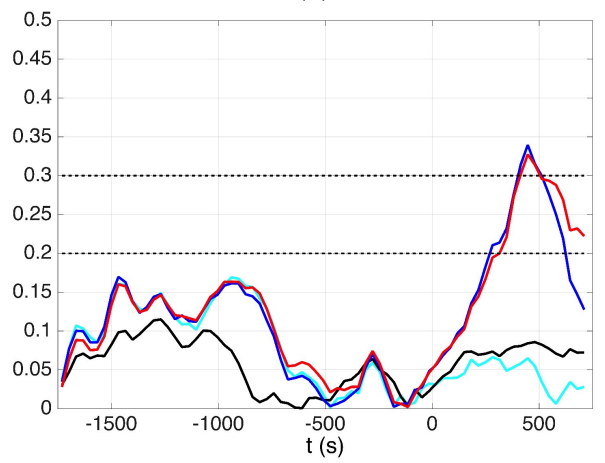

(b)

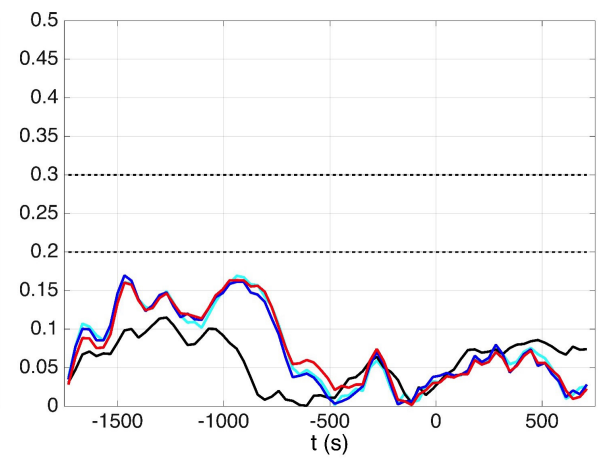

Fig. 6 Time series of the contrast function $\Gamma_{31,23,1}$ computed as a function of time along rays (Fig. 2): (cyan) 160, (black) 180, (blue) 225, (red) 285, for the synthetic SMF source combined with radar data from day 238, with (a) and without (b) a superimposed tsunami; based on a low and high contrast threshold of 0.2 and 0.3 , respectively (horizontal dashed lines), a first warning would be issued $369 \mathrm{~s}(6 \mathrm{~min} 9 \mathrm{sec})$ into the event using rays 225 and 285, and a confirmation of this warning (an alert) would be issued at $519 \mathrm{~s}$ ( 8 min $39 \mathrm{~s}$ ).

\subsection{The influence of sea state}

An important question is whether the efficiency and ability to issue a warning of the TCA are robust to sea state and in which respect the contrast functions shown for the synthetic tsunami test cases are impacted by the variability of the radar data (which is itself related to the variability of oceanic conditions). To answer this question, we applied the algorithm to the few days and hours of radar data which are summarized in Table 1 and evaluated the contrast functions for both the SMF and SSZ tsunami test cases. We found the same trends in contrast function from one day to another as for day 238, but also observed that the function levels was slightly dependent on the selected time period. In some cases, this implied that a warning threshold was reached on a given day but missed on another. This is illustrated in Fig. 7 where the SSZ and SMF contrast functions on ray 225 are evaluated using radar data from five Julian days: 200, 227, 238, 287 and 289. The figure shows, in this case, that the alert threshold would not be reached on day 289 for the 2 tsunamis while a false warning would be triggered. Julian day 289 (October 15, 2016) was a day with a much larger wave height and period $\left(H_{s} \simeq 4.5\right.$ $\mathrm{m}$ and $T_{p} \simeq 10.7 \mathrm{~s}$ at La Perouse Bank station; see Table 1) than for the other trial 
days. An analysis of the full archive of data at La Perouse Bank station during 2016, shows that such a significant wave height, although not exceptional, is quite rare as it belongs to the top $8 \%$ of the recorded values. As of now, we have no definite explanation for the lesser performance of the TCA on a day with a strong sea state, which is an issue that will require further investigation.

For calm or moderate sea states (Julian days 200,227, 238 and 287), we could not establish any systematic relation between the "quality" of the contrast function and sea state parameters. We observed that, similarly to the Doppler Method, the performance of the TCA is primarily impacted by the SNR (which can be defined as the ratio of the Bragg peak and the background power in the HF radar signal) and the strength of the tsunami currents, which depends on local bathymetry. However, as the TCA is not based on inverting radial currents, this algorithm is expected to be more robust to a smaller SNR than the Doppler Method and to be less sensitive to the background oceanic currents. Note that there is no obvious relationship either between sea state and SNR, as the attenuation in the propagation of electromagnetic surface waves over a rough sea is compensated by the increasing strength of the Bragg wave component. Hence, a complete and reliable assessment of the performance of TCA as a function of sea state could only be performed on a statistical basis, by testing a large number of days of radar data and wave rays, which is beyond the scope of this paper.

To further evaluate the robustness of the TCA to strong sea states, we recalculated the same contrast functions along different rays on day 289, for the two synthetic tsunamis (Fig. 8). As seen on the figure, at least in the SSZ case, the simultaneous use of different rays allows to compensate for the loss of quality of the contrast function of individual rays in case of a strong sea state. For the SMF case, the contrast function of the relevant rays (225 and 285) is not sufficiently marked to raise above the alert threshold, which means that the event could be missed if the detection is based on those rays only. This confirms that increasing the number of rays taken into consideration in the calculation of the contrast function improves the probability of detection.

(a)

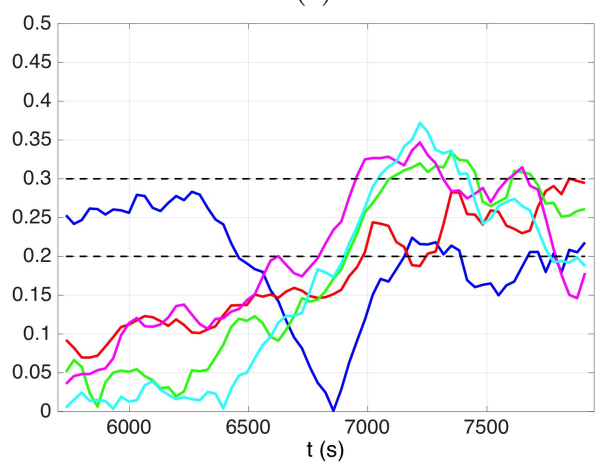

(b)

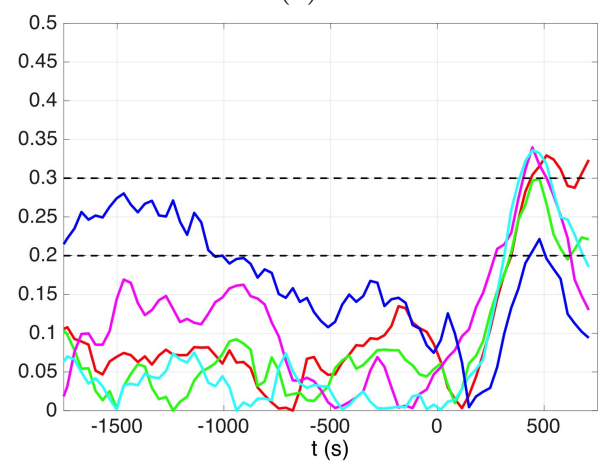

Fig. 7 Time series of contrast function $\Gamma_{31,23,1}$ computed as a function of time along ray 225 (Fig. 2) using the radar data of Julian day: (red) 200, (green) 227, (magenta) 238, (cyan) 287 and (blue) 289, for the synthetic a) SSZ source b) SMF source. 
(a)

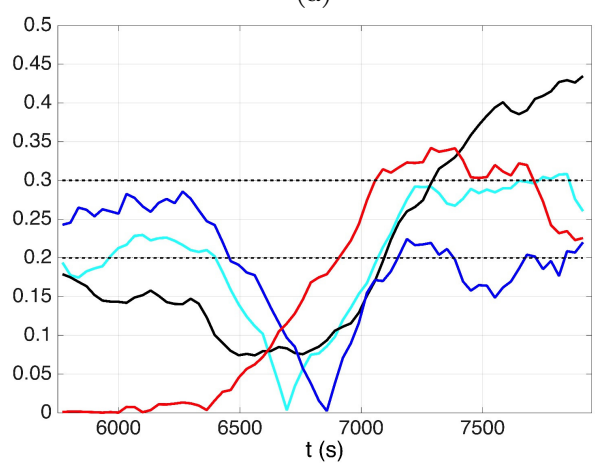

(b)

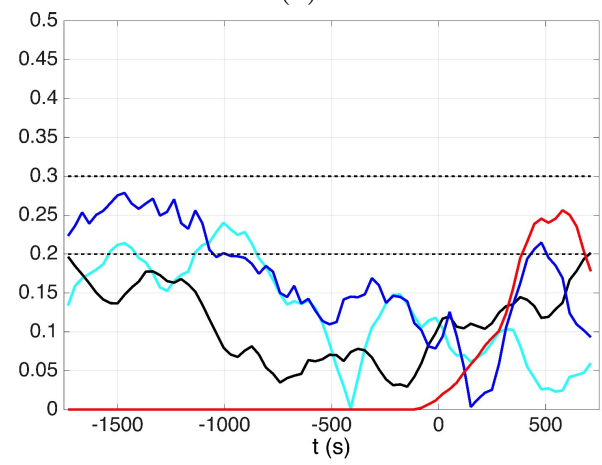

Fig. 8 Time series of contrast function $\Gamma_{31,23,1}$ computed as a function of time along rays (Fig. 2): (cyan) 160, (black) 180, (blue) 225, (red) 285, for the synthetic a) SSZ source b) SMF source combined using radar data from the day with strongest significant wave height (day 289 , October 15, 2016). The alert would still be triggered with rays 160, 180 and 285 for the SSZ source but would be missed with the SMF source.

\section{Offline detection of meteotsunami with the TCA}

\subsection{The October 14th, 2016 event}

On October 14th, 2016, at 6h 06 min UTC, the WERA HF radar installed in Tofino, whose system was running the standard tsunami detection software developed by Helzel Messetechnik GmbH (DM-TDA based), triggered a tsunami alert, as the influence of the approaching typhoon Songda was starting to be felt along the Pacific coasts of the US and Canada. At the time of the alert, longperiod sea level oscillations of $\sim 20 \mathrm{~cm}$ amplitude were clearly measured by some nearby tide gauges and meteorological stations located off of the coast recorded the propagation of a strong low pressure front (of about 980 millibar), moving at an exceptionally high speed of $\sim 95 \mathrm{~km} / \mathrm{h}$ (see Figs. 9 and 10). Since no seismic activity was reported in the region at the time, it seemed that this event could have been of atmospheric origin and, in particular, a meteotsunami. (Dzvonkovskaya et al 2017) provided an initial geophysical interpretation of this event as well as data on current measurements and tsunami detection achieved by the standard TDA that was running in real time in the Tofino HF radar system. If, in research still in progress, this event was confirmed to have indeed been a meteotsunami, it would be the first example in the history of HF radars, of a real time tsunami detection. To date, it is still not definitely established whether this event was caused by a storm surge, a seiche, a meteotsunami, infra-gravity waves, or any combination of these four types of phenomena. A thorough analysis and inclusion of all available geophysical data is necessary to reach more definitive conclusions in this respect. Below, we further analyze this event and then assess the TCA detection performance in this context.

To better understand the event that triggered the tsunami alert in the radar system, we first analyzed time series of radial surface currents inverted from $3 \mathrm{~h}$ of 


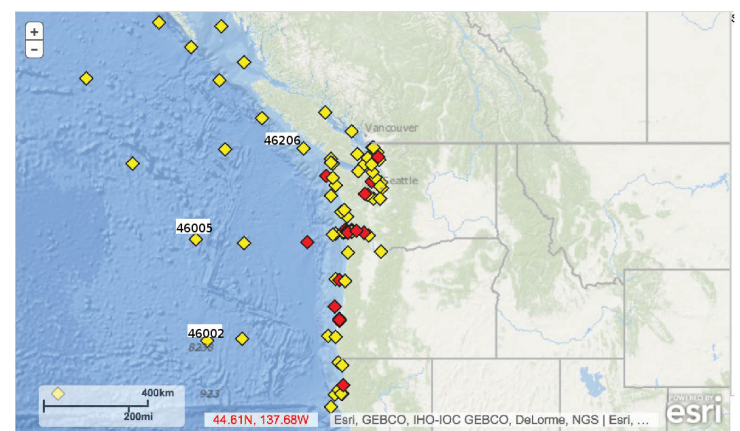

Fig. 9 Location of NOAA meteorological stations 46002, 46005 and 46206.

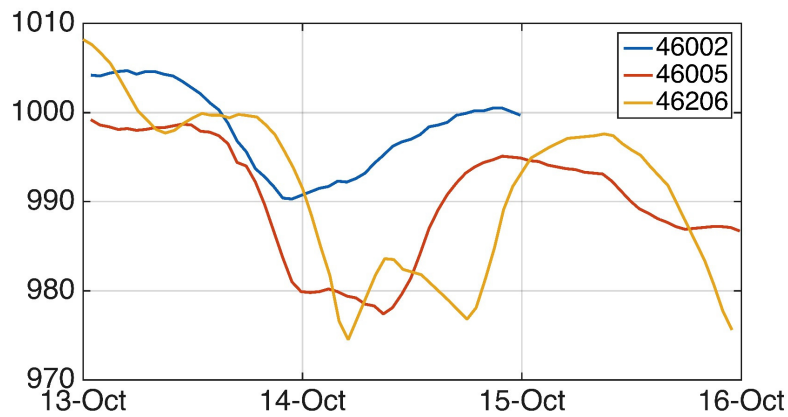

Fig. 10 Time series of atmospheric pressure (millibar) measured at NOAA stations 46002 , 46005 and 46206 (Fig. 6) from October 13-16, 2016. The propagation of a low pressure front towards the NNE, at a speed of about $95 \mathrm{~km} / \mathrm{h}$, is clearly visible.

radar data acquired between $4 \mathrm{~h} 00 \mathrm{~min}$ and $6 \mathrm{~h} 58$ min UTC on 10/14/16. Here, currents were inverted using a Bayesian probabilistic method recently developed by the authors to efficiently and accurately process data originating from phase array systems (Guérin and Grilli 2018). In this method, a Bayesian estimation of the absolute value of the surface currents is calculated based on time series of complex radar signal backscattered from each radar cell, similar to those processed in the TCA. Specifically, a "Maximum A Posteriori Probability Estimate" (MAPPE) is developed using relevant a priori information on the surface currents, which makes it possible inverting currents in a noisy environment with short integration times; as discussed above, the latter is important when dealing with tsunami currents. Figure 11 shows the evolution of the absolute value of radial currents calculated with the MAPPE method over different cell intervals/ranges along azimuth 70 (Fig. 2). Here, $\sim 2$ min sliding intervals (512 samples; $133 \mathrm{~s}$ ) were used to produce surface current time series, with a $16 \mathrm{~s}$ update rate. The a priori probability distribution used in the Bayesian estimation was Gaussian with a mean equal to the average value estimated over the past $264 \mathrm{~s}$ of data and standard deviation set to $15 \mathrm{~cm} / \mathrm{s}$. The starting time in the estimation was $4 \mathrm{~h} 00 \mathrm{~min}$ UTC. Figs. 11a,b,c clearly show a sudden increase in radial current magnitude by $\sim 25-30 \mathrm{~cm} / \mathrm{s}$ (i.e., a current front), at 96 (5h 36 min UTC), 110 (5h 50 min UTC), and 129 (6 h 09 
min UTC) min, over cells 40-41, 30-31 and 20-21, respectively. A similar analysis made in other azimuthal directions on either side of azimuth 70 (not shown here) yielded a consistent, albeit less pronounced, behavior, supporting the hypothesis that this unusual current pattern followed a main direction of propagation close to azimuth 70 .

The speed of propagation of the observed current front can approximately be estimated by dividing cell range interval by time difference between Figs. 11a, b and c. Thus, as the current front occurs at 5:36' at range 40 and 5:50' at range 30 , a $15 \mathrm{~km}$ propagation takes place in $14 \mathrm{~min}$, yielding a $64 \mathrm{~km} / \mathrm{h}$ propagation speed between these two locations. Similarly, at range 20 the front is seen at 6:09', which in turn implies a propagation speed of $47 \mathrm{~km} / \mathrm{h}$ between ranges 30 and 20 .

Considering the bathymetry variation under azimuth 70 (Fig. 12), these propagation speeds are close to the long wave celerity $c=\sqrt{g h}$ computed from the local bathymetry $h$ : in average, $65 \mathrm{~km} / \mathrm{h}$ between cells 40 and 30 and $55 \mathrm{~km} / \mathrm{h}$ between cells 30 and 20 . If it turns out that the propagating current front is caused by an atmospheric disturbance, this close correspondence with the local free long wave speed would support the occurrence of a Proudman resonance and, hence, the hypothesis of a meteotsunami (Monserrat et al 2006). However, we had no atmospheric data at our disposal to calculate the speed of the pressure front in the radar sweep area and could only roughly evaluate it between the remote meteorological stations 46002, 46005 and 46206 (Fig. 9 and 10), where it was estimated to be $95 \mathrm{~km} / \mathrm{h}$. Nethertheless, the likely slow-down of the low pressure front when approaching the coast, e.g., as a result of land friction, could have made its speed match that of the propagating current front in the radar sweep area.

\subsection{Detection of a potential meteotsunami event with the TCA}

In the following, we investigate whether the TCA would have detected the October 14th, 2016 event, had it been running in real time on the radar system, and estimate when a first warning could have been issued. To do so, we applied the TCA to the Tofino radar data acquired over the sweep area during the time period surrounding the occurrence of the candidate meteotsunami event, i.e., 4h $00 \mathrm{~min}$ to $7 \mathrm{~h} 00 \mathrm{~min}$ UTC. Unfortunately, no data were available after $7 \mathrm{~h} 00 \mathrm{~min}$, as the storm associated with this event caused an electrical outage in Tofino. Figure 13 shows time series of contrast functions calculated along the 6 rays shown in Fig. 2 , which cover well the entire sweep area. Although an operational TDA would systematically check a large number of possible cell intervals on each selected wave ray, here for illustration we used 3 relevant cell intervals on each ray, namely cells 20 to 30 (Figs. 13a,b), 30 to 40 (Fig. 13c,d), and 40 to 50 (Fig. 13e,f). Radar data in each cell within these ranges was correlated with that of its neighboring cell range-ward, yielding 21 correlation pairs $\left(C_{30-31}, C_{31-32}, \ldots, C_{50-51}\right)$. The reference correlations necessary to evaluate the contrast functions were obtained by calculating the same quantities one hour in the past, hence before tsunami arrival. An integration window of $T_{c}=900 \mathrm{~s}$ in the past was used, which was found to be a good compromise between obtaining stable estimates of the average correlations and capturing the transient effects caused by the current front. Based on these correlations, 3 one-hour time series of contrast functions were computed: 
(a)

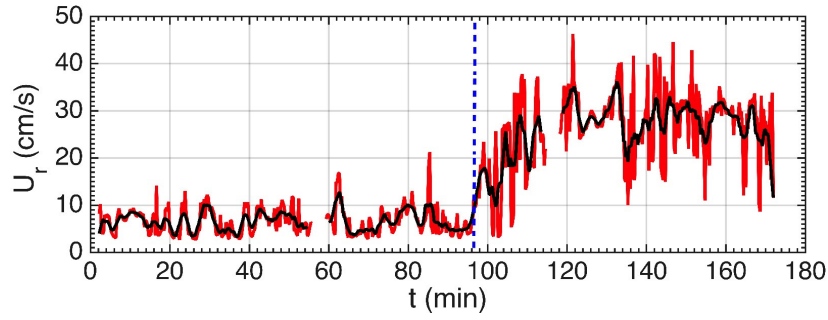

(b)

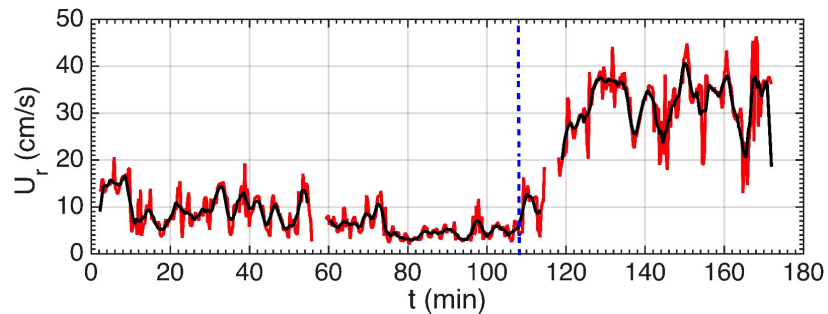

(c)

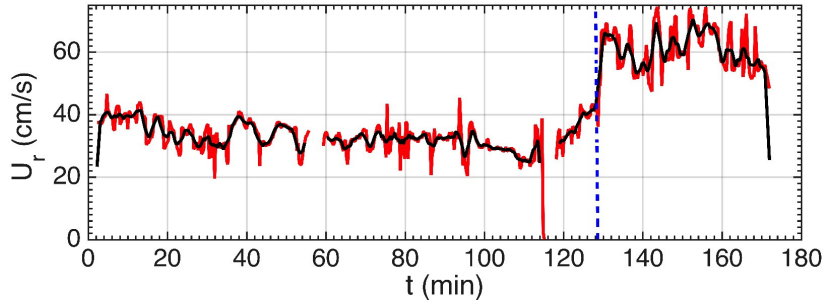

Fig. 11 Time series of inverted radial surface currents (red lines), and smoothed currents (black lines) computed on October 14th, 2016 (day 288) along azimuth 70 (Fig. 2), averaged over cells/ranges: (a) 40-41; (b) 30-31; and (c) 20-21 (the time origin is at $4 \mathrm{~h} 00 \mathrm{~min}$ UTC). Radial currents are estimated every $16 \mathrm{~s}$ using the MAPPE method ((Guérin and Grilli 2018)), for overlapping intervals of 512 points $(133 \mathrm{sec})$. The occurrence of a jump in current magnitude is clearly visible in figures (a-c), at 96 (5h 36 min UTC), 108 (5h 48 min UTC) and 129 (6h 09 min UTC) min, respectively (marked by a vertical dashed line), which propagates from ranges 40 , to 30 and 20 .

$\Gamma_{20,11,1}, \Gamma_{30,11,1}, \Gamma_{40,11,1}$, from $5 \mathrm{~h} 00 \mathrm{~min}$ to $6 \mathrm{~h} 00 \mathrm{~min}$ and $6 \mathrm{~h} 00 \mathrm{~min}$ to $7 \mathrm{~h} 00$ min UTC in Figs. 13a,c,e and Figs. 13b,d,f, respectively.

Assuming contrast thresholds of $0.3-0.4$ or $0.2-0.4$, Fig. 13 shows that, based on the contrast functions computed for rays 180,225 and 235 over cells $30-40$ (45-60 km), a first warning could have been issued by the TCA-TDA at 5h 49 min UTC (Fig. 13c) and confirmed at $5 \mathrm{~h} 55$ min UTC (Fig. 13e). This would have been triggered by the strong increase in contrast function on ray 180, over cells 40-50 (60-75 km). Based on the even more drastic increase in contrast function on rays 160 and 180 over cells 40-50 (Fig. 13f) confirmed by the large increase in contrast functions of the entire group of rays over cells 30-40 (Fig. 13d), a second alert could have been issued at about $6 \mathrm{~h} 35 \mathrm{~min}$. Note that the non-monotonic behavior of the contrast function, with the occurrence of two maxima separated in time by 40 minutes ( $5 \mathrm{~h} 55 \mathrm{~min}$ and $6 \mathrm{~h} 35 \mathrm{~min}$ ), is consistent with the tsunami alert 


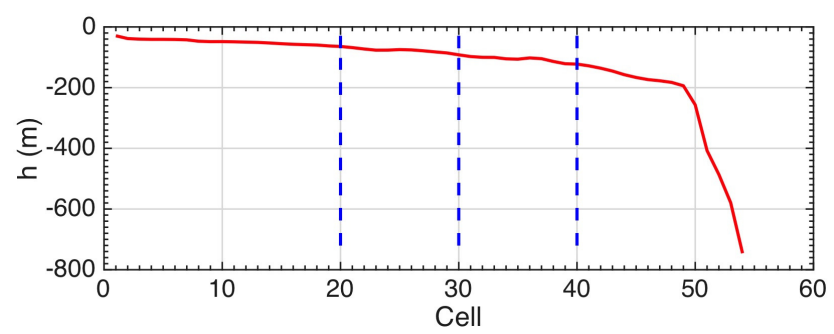

Fig. 12 Bathymetry transect along azimuth 70 (Fig. 2).

map issued by the radar system, which is reproduced in Fig. 4 of (Dzvonkovskaya et al 2017), where the alert threshold was reached twice at about the same time. The second alert could correspond to a second, stronger, incoming tsunami wave of tsunami. Unfortunately, the October 14th, 2016, storm caused an electrical outage at about $7 \mathrm{~h} 00$ min UTC, resulting in a few hours of interruption in the HF radar records. It would have been interesting to check for the arrival of subsequent waves and possible alerts, to confirm the tsunami-like nature of this event.

\section{Probability of false alarms}

In the TCA, the choice of the low and high contrast thresholds used for issuing a tsunami warning and an alert, respectively, is a delicate matter, which would require a thorough statistical analysis of radar time series under various oceanic conditions. In light of such an analysis, the selected thresholds would then result from a trade-off between the probability of detection $\mathrm{P}(\mathrm{D})$ and the probability of false alarms $\mathrm{P}(\mathrm{F})$. In the TCA, besides the selected thresholds, these probabilities will also depend on the choice of radar cells, integration time used to evaluate the correlations, and selected wave rays. While it is difficult to evaluate $P(D)$, as this would require performing statistics over many actual tsunamis, $\mathrm{P}(\mathrm{F})$ can more easily be computed by estimating the probability of the contrast function to reach a given pre-set contrast threshold in the absence of a tsunami, which only requires a statistical analysis of archived radar data representative of various oceanic conditions. Thus, for a given contrast threshold $\Gamma_{\epsilon}, \mathrm{P}(\mathrm{F})$ could be defined as the number of occurrences of the contrast function exceeding this threshold $\left(\Gamma>\Gamma_{\epsilon}\right)$ divided by the total number of available values of the contrast function. Here, a very crude estimate of $\mathrm{P}(\mathrm{F})$ was calculated this way based only on the few hours/days of radar data under consideration. Figure 14 shows $\mathrm{P}(\mathrm{F})$ calculated as a function of the contrast threshold for 4 rays $(160,180,225,285$; Fig. 2; only the most relevant rays for this case were processed) and contrast functions $\Gamma_{20,11,1}$, $\Gamma_{30,11,1}$, and $\Gamma_{40,11,1}$, used in the above meteotsunami detection study. As can be seen, a detection criterion based on the lowest thresholds 0.2 and 0.3 as used in Figs. 13c,e, would trigger a warning with a nearly zero rate of false alarms. Note that the estimation of $\mathrm{P}(\mathrm{F})$ could be refined by requiring that the contrast function exceed some threshold for several rays simultaneously (instead of one at a time), a task which has not been performed here. 
(a)

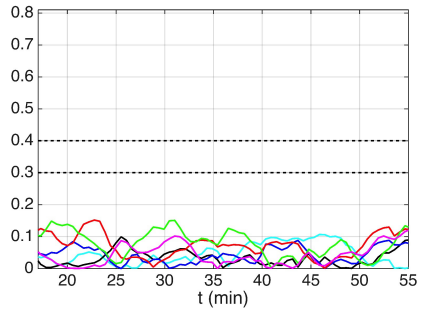

(c)

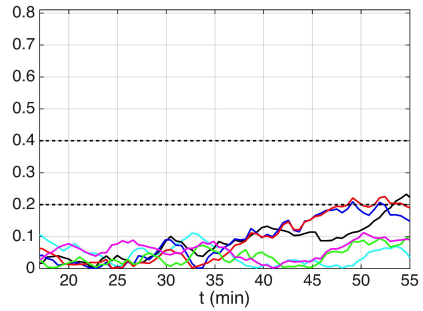

(e)

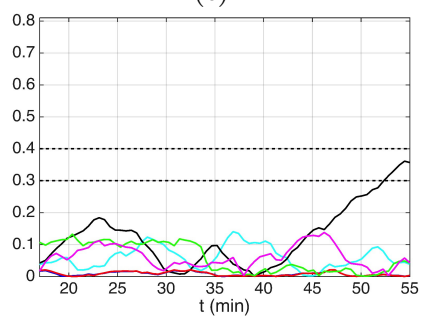

(b)

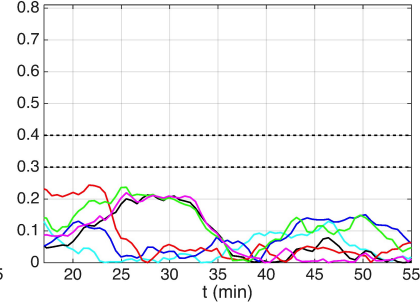

(d)

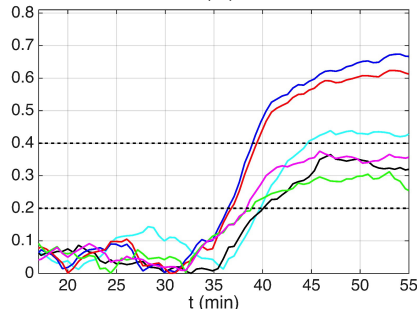

(f)

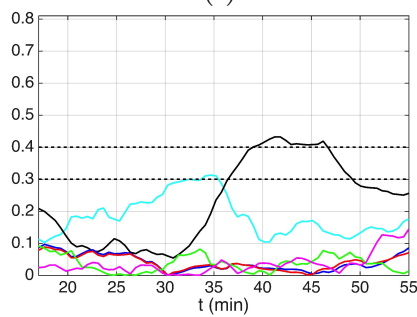

Fig. 13 Zoom on 1h contrast function time series computed on October 14th, 2016 (day 288) with $T_{c}=900 \mathrm{~s}$ (in the past), along rays (Fig. 2): (cyan) 160, (black) 180, (blue) 225, (red) 285, (green) 165 (I) and (magenta) 165 (II). (a) and (b): $\Gamma_{20,11,1}$ (i.e., using the combination of gates $(20: 30)+1)$; (c) and (d) $\Gamma_{30,11,1} ;$ (e) and (f) $\Gamma_{40,11,1}$. The origin of time is $5 \mathrm{~h} 00 \mathrm{~min}$ UTC in the leftward column ( $\mathrm{a}, \mathrm{c}$ and e) and $6 \mathrm{~h} 00$ min UTC in the rightward column (b, d and f). Arbitrary contrast threshold values have been marked by black dashed lines.

The low and nearly zero probability of false alarms observed at the low (0.2) and high (0.3) thresholds, respectively, confirm the effectiveness of an alert issued by the TCA, based on a threshold exceedance, such as done above in Fig. 13.

\section{Discussion and conclusions}

In this study, we further assessed and tested the tsunami detection ability of the Time Correlation Algorithm (TCA) proposed by (Grilli et al 2016a, 2017), based on using actual data from the Tofino HF radar, either combined with realistic site specific tsunami simulations or "as is" for the potential meteotsunami event of October 14th, 2016. The analysis showed that the original TCA, initially validated with synthetic radar data, had to be refined and adjusted to account for the preexisting correlation of radar signal backscattered from different cells, which is an artifact of the range and azimuth processing algorithms applied to the raw radar 
(a)

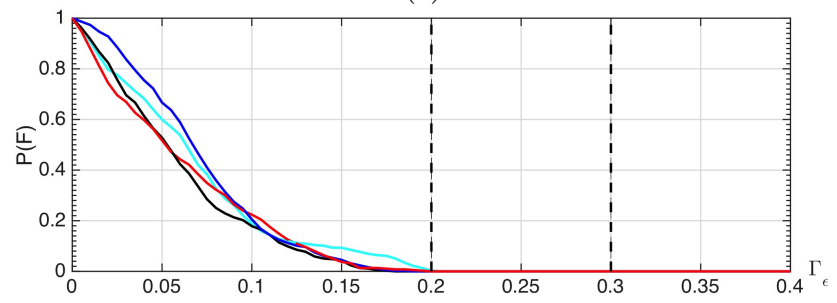

(b)

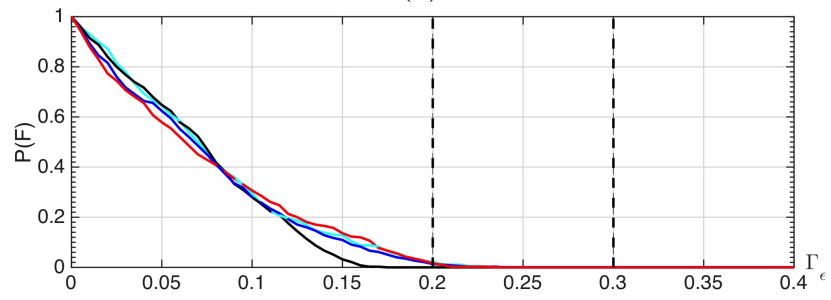

(c)

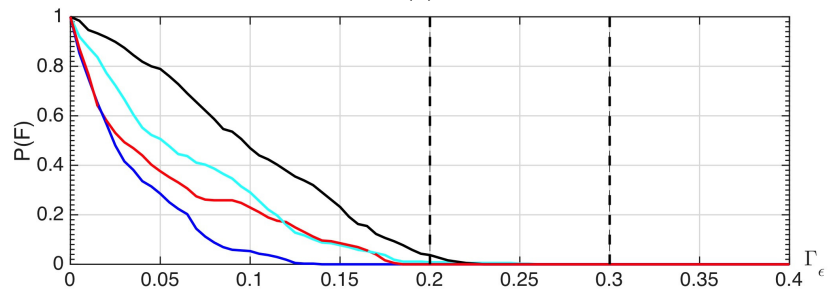

Fig. 14 Same data and case as in Fig. 13. Probability of false alarms as a function of contrast function threshold, for a tsunami warning issued by the TCA, based on the magnitude of the radar contrast function: (a) $\Gamma_{20,11,1}$; (b) $\Gamma_{30,11,1}$; and (c) $\Gamma_{40,11,1}$, along rays (Fig. 2): (cyan) 160, (black) 180, (blue) 225 and (red) 285.

data. This was done by calculating a so-called contrast function, which quantifies the change in pattern of the mean correlation between pairs of neighboring radar cells upon tsunami arrival, with respect to a reference correlation computed in the recent past. In the paper, we showed, using two synthetic but realistic tsunamis case studies (for a large far-field co-seismic and a near-field SMF tsunamis), that a marked change in contrast function can be used as a relevant proxy for tsunami detection, which allows issuing a timely warning, confirmed by an alert. Note that different integration times were used in the TCA for the detection of the SMF and SSZ tsunamis, as the time scale of observation must be adapted to the tsunami characteristic period. This requires some a priori knowledge of the type of events that could possibly be detected at a given site. If tsunamis with very different time scales are plausible at the same location (e.g., longer tsunamis from seismic sources and shorter tsunamis from SMF or atmospheric sources), the TCA could easily be run in sequence (or in parallel) using multiple integration times.

The TCA tsunami detection performance was then further tested based on an actual event, which occurred on October 14th, 2016 and triggered a tsunami alert in the standard monitoring software running on the Tofino WERA system. Here, we performed an a posteriori (i.e., offline) analysis of both the meteorological and 
radar data acquired during the 2 hours surrounding the alert (i.e., from $5 \mathrm{~h} 00 \mathrm{~min}$ to $7 \mathrm{~h} 00 \mathrm{~min}$ UTC). The identification of a high-speed propagating low pressure front along the US and Canadian West coasts, and a corresponding marked current front in the radar sweep area traveling at a local long wave celerity supports the hypothesis of a meteotsunami, although the occurrence of another type of unusual long wave phenomenon (e.g., seiche, storm surge, infra-gravity waves) cannot yet be ruled out. The exact nature of this event could be elucidated both by conducting a more thorough multi-sensor geophysical analysis and numerical simulations of tsunami generation by the observed pressure perturbation; the latter are the object of ongoing work. To assess its detection performance for this event, the TCA was applied along 6 rays covering the entire radar sweep area and the contrast function was evaluated for pairs of adjacent radar cells along the rays, in the close- (cells 20-30, 30-45 km), intermediate- (cells 30-40, 45-60 km) and far-ranges (cells 40-50, $60-75 \mathrm{~km}$ ). Using an appropriate contrast function threshold value in the TCA, a first warning based on results from different rays could have been issued as early as 5 h 49 min UTC.

The determination of optimal contrast function threshold values, in terms of maximizing the probability of detection and minimizing that of false alarms, would require a long-term assessment, over at least a full year of radar data corresponding to a large variety of oceanic conditions. Such a thorough statistical analysis was recently performed, using a Doppler-based algorithm, using HF radar data acquired in Japan (Fuji and Hinata 2017), where a detection probability could be estimated by combining synthetic (numerical) tsunamis with one month of actual $\mathrm{HF}$ radar measurements. It was found that the detection probability crucially depends on the tsunami to background current energy ratio. This limitation is in principle relaxed with the TCA, where the correlation analysis is performed on the radar signal itself and, hence, does not depend on the background current. In addition, the TCA performance could be refined by optimizing the cell ranges and rays used in the analysis. Both of these aspects will be addressed next in our work as they are necessary steps to develop a truly operational TDA system, which could be used as a useful complement to existing algorithms. This will be part of future work.

Acknowledgements The authors wish to thank Helzel Messtechnik GmbH (in particular Dr. A. Dzvonkovskaya) for technical support to process the radar data and Ocean Networks Canada for providing the WERA HF radar data and support to the University of Rhode Island to conduct this research. C.-A. Guérin also acknowledges the CNRS, the University of Toulon, and the French-American Fulbright commission for supporting his sabbatical leave at URI.

\section{References}

Abadie S, Harris JC, Grilli ST, Fabre R (2012) Numerical modeling of tsunami waves generated by the flank collapse of the Cumbre Vieja Volcano (La Palma, Canary Islands) : tsunami source and near field effects. J Geophys Res 117:C05,030, DOI 10.1029/2011JC007646

Barrick DE (1972a) First-order theory and analysis of MF/HF/VHF scatter from the sea. IEEE Transactions on Antennas and Propagation 20(1):2-10

Barrick DE (1972b) Remote sensing of sea state by radar. In: IEEE International Conference on Engineering in the Ocean Environment, Ocean 72, IEEE, pp 186-192

Barrick DE (1972c) Remote sensing of sea state by radar. In: Remote sensing of the Troposphere, VE Derr, Editor, US Government, vol 12 
Barrick DE (1972d) Remote sensing of the troposphere. Remote Sensing of Sea State by Radar pp $1-46$

Barrick DE (1978) HF radio oceanography: a review. Boundary-Layer Meteorology 13(1-4):2343

Barrick DE (1979) A coastal radar system for tsunami warning. Remote Sensing of Environment 8(4):353-358

Benjamin LR, Flament P, Cheung KF, Luther DS (2016) The 2011 Tohoku tsunami south of Oahu: high-frequency Doppler radio observations and model simulations of currents. J Geophys Res (publ online) 121(2):1133-1144, DOI 10.1002/2015JC011207

Bernard E, Titov V (2016) Evolution of tsunami warning systems and products. Phil Trans R Soc Lond A 373(2053):20140,371, DOI 10.1098/rsta.2014.0371.

Crombie DD (1955) Doppler spectrum of sea echo at $13.56 \mathrm{Mc}$./s. Nature pp 681-682

Dzvonkovskaya A, Petersen L, L IT (2017) Real-time capability of meteotsunami detection by WERA ocean radar system. In: 8th Intl. Radar Symp. (IRS 2017, June 28-30, 2017, Prague, Czech Republic), p 10 pps.

Fine I, Rabinovich A, Bornhold B, Thomson R, Kulikov E (2005) The Grand Banks landslidegenerated tsunami of November 18, 1929: preliminary analysis and numerical modelling. Mar Geol 215:45-57, DOI 10.1016/j.margeo.2004.11.007

Fuji R, Hinata H (2017) Temporal variability of tsunami arrival detection distance revealed by virtual tsunami observation experiments using numerical simulation and 1-month hf radar observation. Journal of Oceanography pp 1-17

Grilli ST, Ioualalen M, Asavanant J, Shi F, Kirby JT, Watts P (2007) Source constraints and model simulation of the December 26, 2004 Indian Ocean tsunami. Journal of Waterway Port Coastal and Ocean Engineering 133(6):414-428, DOI 10.1061/(ASCE)0733950X(2007)133:6(414)

Grilli ST, Harris JC, Tajalli-Bakhsh T, Masterlark TL, Kyriakopoulos C, Kirby JT, Shi F (2013) Numerical simulation of the 2011 Tohoku tsunami based on a new transient FEM co-seismic source: Comparison to far- and near-field observations. Pure and Applied Geophysics 170:1333-1359, DOI 10.1007/s00024-012-0528-y

Grilli ST, O'Reilly C, Harris J, Tajalli-Bakhsh T, Tehranirad B, Banihashemi S, Kirby J, Baxter C, Eggeling T, Ma G, Shi F (2015) Modeling of SMF tsunami hazard along the upper US East Coast: Detailed impact around Ocean City, MD. Natural Hazards 76(2):705-746, DOI 10.1007/s11069-014-1522-8

Grilli ST, Grosdidier S, Guérin CA (2016a) Tsunami detection by High Frequency Radar beyond the continental shelf. I. Algorithms and validation on idealized case studies. Pure and Applied Geophysics 173(12):3,895-3,934, DOI 10.1007/s00024-015-1193-8

Grilli ST, Shelby M, Grilli A, Guérin CA, Grosdidier S, Insua TL (2016b) Algorithms for tsunami detection by high frequency radar: Development and case studies for tsunami impact in british columbia, canada. In: Proc. 26th Intl. Ocean and Polar Engng. Conf. (ISOPE16, Rodos, Greece. June 2016)., International Society of Offshore and Polar Engineers, pp pps. 807-814

Grilli ST, Guérin CA, Shelby M, Moran P, Grosdidier S, Insua TL (2017) Tsunami detection by High Frequency Radar beyond the continental shelf: II. Extension of algorithms and validation on realistic case studies. Pure and Applied Geophysics 174(1):3,003-3,028, DOI 10.1007/s00024-017-1619-6

Guérin CA, Grilli S (2018) A probabilistic method for the estimation of ocean surface currents from short time series of HF radar data. Ocean Modelling 121:105-116

Guérin CA, Grilli S, Moran P, Grilli A, Insua TL (2017) Tsunami detection by High Frequency Radar using a Time-Correlation Algorithm: performance analysis based on data from a HF radar in British Columbia. In: Proc. 27th Intl. Offshore and Polar Engng. Conf. (ISOPE17, San Francisco, USA. June 2017)., International Society of Offshore and Polar Engineers, pp pps. 930-936

Gurgel KW, Dzvonkovskaya A, Pohlmann T, Schlick T, Gill E (2011) Simulation and detection of tsunami signatures in ocean surface currents measured by HF radar. Ocean Dynamics 61(10):1495-1507

Heron ML, Prytz A, Heron SF, Helzel T, Schlick T, Greenslade DJ, Schulz E, Skirving WJ (2008) Tsunami observations by coastal ocean radar. International Journal of Remote Sensing 29(21):6347-6359

Hinata H, Fujii S, Furukawa K, Kataoka T, Miyata M, Kobayashi T, Mizutani M, Kokai T, Kanatsu N (2011) Propagating tsunami wave and subsequent resonant response signals 
detected by HF radar in the Kii Channel, Japan. Estuarine, Coastal and Shelf Science 95(1):268-273

Ioualalen M, Asavanant J, Kaewbanjak N, Grilli ST, Kirby JT, Watts P (2007) Modeling the 26th December 2004 Indian Ocean tsunami: Case study of impact in Thailand. J Geophys Res 112:C07,024, DOI 10.1029/2006JC003850

Kirby S, Scholl D, Von Huene R, Wells R (2013) Alaska earthquake source for the SAFRR tsunami scenario. Tech. Rep. USGS Report, 2013, U.S. Geological Survey Open-File . http://pubs.usgs.gov/of/2013/1170/b/, The SAFRR (Science Application for Risk Reduction) Tsunami Scenario

Lipa B, Barrick D, Saitoh SI, Ishikawa Y, Awaji T, Largier J, Garfield N (2011) Japan tsunami current flows observed by HF radars on two continents. Remote Sensing 3(8):1663-1679

Lipa B, Isaacson J, Nyden B, Barrick D (2012a) Tsunami arrival detection with high frequency (HF) radar. Remote Sensing 4(5):1448-1461

Lipa BJ, Barrick DE, Bourg J, Nyden BB (2006) HF radar detection of tsunamis. Journal of Oceanography 62(5):705-716

Lipa BJ, Barrick DE, Diposaptono S, Isaacson J, Jena BK, Nyden B, Rajesh K, T K (2012b) High frequency (HF) radar detection of the weak 2012 Indonesian tsunamis. Remote Sensing 4:2944-2956

Lipa BJ, Parikh H, Barrick DE, Roarty H, Glenn S (2014) High frequency radar observations of the June 2013 US East Coast meteotsunami. Natural Hazards 74:109-122

Ma G, Shi F, Kirby JT (2012) Shock-capturing non-hydrostatic model for fully dispersive surface wave processes. Ocean Modeling 43-44:22-35, DOI 10.1016/j.ocemod.2011.12.002

Monserrat S, Vilibić I, Rabinovich AB (2006) Meteotsunamis: atmospherically induced destructive ocean waves in the tsunami frequency band. Natural Hazards and Earth System Science 6:1035-1051

Mori N, Takahashi T, Group TETJS (2012) Nationwide post event survey and analysis of the 2011 tohoku earthquake tsunami. Coastal Engineering Journal 54(01):1250,001

Stewart RH, Joy JW (1974) HF radio measurements of surface currents. In: Deep Sea Research and Oceanographic Abstracts, Elsevier, vol 21(12), pp 1039-1049

Tappin DR, Watts P, Grilli ST (2008) The Papua New Guinea tsunami of 1998: anatomy of a catastrophic event. Natural Hazards and Earth System Sciences 8:243-266, DOI www.nathazards-earth-syst-sci.net/8/243/2008/

Tehranirad B, Harris J, Grilli A, Grilli S, Abadie S, Kirby J, Shi F (2015) Far-field tsunami hazard in the north Atlantic basin from large scale flank collapses of the Cumbre Vieja volcano, La Palma. Pure and Applied Geophysics 172(12):3,589-3,616, DOI 10.1007/s11069-014$1522-8$

Thomson RE, Rabinovich AB, Fine IV, Sinnott DC, McCarthy A, Sutherland NAS, Neil LK (2009) Meteorological tsunamis on the coasts of British Columbia and Washington. Physics and Chemistry of the Earth Parts A/B/C 34(17):971-988

Titov V, Rabinovich A, Mofjeld H, Thomson R, Gonzalez F (2005) The global reach of the 26 December 2004 Sumatra tsunami. Science 309(5743):2045-2048 